\title{
В.Г. БОГОРАЗ КАК ЮКАГИРОВЕД
}

В статье рассматривается вклад В.Г. Богораза в изучение этногенеза, хозяйства, фольклора и духовной культуры юкагиров. Автор подчеркивает, что, хотя Владимир Германович специально не занимался изучением этого народа, он сделал иеннье наблюдения, касающиеся взаимодействия юкагиров и чукчей, эвенов, русских старожилов, и нашел параллели в хозяйственной деятельности и культуре этих народов. Идеи ученого в области этногенеза и ранней этнической истории юкагиров в целом соответствуют современным представлениям, хотя о происхождении этого народа до сих пор идут дискуссии. В статье подчеркивается, что знаменитый труд В.Г. Богораза «Чукчи» вносит заметный вклад и в изучение этнографии юкагиров, их хозяйства и культуры конца XIX в.

Ключевые слова: В.Г. Богораз, палеоазиатские народы, юкагиры, чукчи, эвеHbl, этногенез, хозяйство, духовная культура, фольклор, шаманство

Ссылка при цитировании: Бурыкин А.А. В.Г. Богораз как юкагировед // Вестник антропологии, 2022. № 1. С. 312-325.

DOI: $10.33876 / 2311-0546 / 2022-1 / 312-325$

(C) A.A. Burykin

\section{V.G. BOGORAZ AS A RESEARCHER OF YUKAGIRS}

The article highlights the contribution of V.G. Bogoraz to the study of ethnogenesis, economy, folklore and spiritual culture of the Yukagirs. The author shows that although V.G. Bogoraz did not specifically deal with the Yukagirs, he made and summarized many valuable observations on the interaction of the economy and culture of the Yukaghirs with the culture of the Chukchee, Evens, and Russian old-timers. The scientist's ideas on ethnogenesis and the early ethnic history of the Yukagirs are generally consistent with modern ideas, although the problem of the origin of the Yukagirs has not yet been resolved. The ideas and observations of V.G. Bogoraz contained in his famous work "The Chukchee" (Russian translation of parts I-II, L., 1934, 1939) make a significant contribution to the study of the ethnography of the Yukagirs, of their economy and culture at the end of the 19th century.

Keywords: V.G. Bogoraz, Paleosiberian peoples, Yukagirs, Chukchee, Evens, ethnogenesis, economy, spiritual culture, folklore, shamanism

For Citation: Burykin, A.A. 2022. V.G. Bogoraz as a Researcher of Yukagirs. Herald of Anthropology (Vestnik Antropologii) 1: 312-325.

Бурыкин Алексей Алексеевич (1954-2021) - д.и.н., д. филол. наук, ведущий научный сотрудник, Институт лингвистических исследований РАН (199004 Санкт-Петербург Тучков пер., 9) 
Author Info: Burykin, Aleksey A. (1954-2021) - Dr. of History, Dr. of Philology, Leading Researcher, Institute for Linguistic Studies of the Russian Academy of Sciences (St. Petersburg, Russia).

В.Г. Богораз (Тан-Богораз, Богораз-Тан) (1865-1936) вошел в историю отечественной этнографической науки прежде всего как исследователь народов, которых принято называть северо-восточными палеоазиатами: чукчей, коряков, эскимосов, эвенов (Цинциус 1967). В ХХ в. проблемы этнографии этих народов и их соседей активно изучались выдающимися представителями советской школы североведения И.С. Вдовиным, И.С. Гурвичем, Б.О. Долгих, Е.А. Крейновичем и другими.

Первое этнографическое описание юкагиров принадлежит перу российского путешественника, географа, лингвиста и этнографа Я.И. Линденау (1700-1795) (Линденау 1983: 154-156). Но основоположником научного изучения этого народа справедливо считается современник В.Г. Богораза В.И. Иохельсон (1855-1937), автор знаменитого исследования «Юкагиры и юкагиризированные тунгусы» (Иохельсон 2005). Во второй половине XX в. был опубликован ряд научных трудов, посвященных истории, этнографии и антропологии юкагиров (Окладников 1975; Туголуков 1979). Работа была продолжена и в ХХІ в. - в первую очередь следует отметить Л.Н. Жукову, автора нескольких монографий, учебных пособий, статей и получивших широкую известность «Очерков по юкагирской культуре» (в 3-х ч.) (Жукова 2003, 2009, 2012, 2013). В 2010 г. в серии «Народы и культуры» вышел том «Народы Северо-Востока Сибири», в котором есть и очерк «Юкагиры» (Плужников, Шадрин 2010: 677-685). Фактически изучение юкагиров как этноса сложилось в самостоятельную традицию и в лингвистике, и в фольклористике, и в археологии (Кирьяк 1993; Жукова 2003), и в этнографии. Несмотря на такой интерес к проблеме, работы В.Г. Богораза, посвященные юкагирам и содержащие полевые наблюдения, сделанные ученым в местах их проживания, до сих пор не были в должной мере востребованы.

Современные антропологи отдают дань уважения В.Г. Богоразу как ученому-этнографу мирового уровня (Михайлова 2004; Kan 2006; Крупник 2008). Его заслуги как собирателя и исследователя фольклора народов Северо-Востока Азии по достоинству оценены и признаны специалистами (Беликов 1967; Зеленин 1937; Колесницкая 1971). Владимир Германович и его супруга Софья (см. о ней: Михайлова 2016) были первыми учеными, собравшими образцы фольклора в бассейне Анадыря, где помимо чукчей жили и родственные юкагирам ходынцы, анаулы и чуванцы (Bogoras 1918). В 1990-х годах были опубликованы ранее неизвестные записи фольклорных материалов русскоязычных чуванцев и их потомков, сходные по фактуре и сюжетике с зафиксированными В.Г. Богоразом (Жихарев 1992; Уваровская 1992). Интересно, что сохранение архаического старожильческого фольклора Владимир Германович приписывает юкагирам: «В далеком колымском краю, на крайнем севере Якутской области обруселые юкагиры еще до конца XIX века выпевали некоторые из этих “старин” (былин)» (Богораз 2018: 151).

Описывая разные самодийские народы, ученый зачастую проводит параллели между ними, обращаясь в том числе и к юкагирам. Так, упоминая щуку - тотем, встречающийся в «Калевале», В.Г. Богораз замечает:

Скажу, кстати, что такими огромными щуками наполнены легенды сибирского севера. Юкагирский охотник на неведомом озере наехал челноком на чудо- 
вищную рыбу. То была щука. Один глаз ее он увидел слева, а другой - далеко справа. Его двойное весло, длиною в сажень, трижды могло уложиться между страшными глазами (Там же: 161).

Юкагирская тема занимает важное место в программной междисциплинарной работе ученого «Древние переселения народов в северной Евразии и в Америке» (Богораз 1927). В.Г. Богораз отделяет юкагиров и чуванцев от чукчей и эскимосов, а о долганах пишет так:

Ряд других племен, обитающих в арктической Азии и в более южных горных областях Сибири кажутся мне примыкающими к палеоазиатам. Таковы на севере долганы, племя неизвестного происхождения, обитающее по реке Хатанге и у озера Ессей, на стыке между самоедами и якутами. Долганы считаются отраслью тунгусов, усвоившей ныне якутский язык. Я склоняюсь к тому, чтобы считать долганов наиболее западной отраслью восточных палеоазиатов, родственной вероятно юкагирам. Юкагиры на всем протяжении от Лены до Алазеи тоже сперва подверглись тунгусской, а потом якутской ассимиляции (Богораз 1927: 41).

Здесь с В.Г. Богоразом трудно согласиться, ни в языке, ни в этнографии долган не выявляются юкагирские параллели, чукотские заимствования тоже не бросаются в глаза, хотя патронимия Каранто (чук. құоранто - «происходящий от оленей») вполне может иметь чукотское происхождение за счет позднейших контактов. В.Г. Богораз отмечает, что оленеводство без использования пастушеской собаки характерно для чукчей, коряков, чуванцев и юкагиров, северных тунгусов и якутов (Там же: 44). Это замечание ученого бесспорно и абсолютно верно, равно как и наблюдения над характером оленеводства в Евразии и рассуждения о его происхождении.

Интересна следующая мысль В.Г. Богораза: «...юкагиры, а также вероятно и долганы, подверглись тунгусификации. Можно полагать, что и среди амурских племен, особенно в области устья, мы имеем древне-азиатов, усвоивших тунгусский язык. Таковы, быть может, орочи и ольчи» (Богораз 1927: 61). Эта мысль высказывалась ученым и в монографическом издании «Чукчи» (Богораз 1934: 41, 61).

Относительно долган взгляды В.Г. Богораза требуют пересмотра, что касается тунгусификации юкагиров, то здесь Владимир Германович прав - и в гораздо большей степени, чем некоторые современные юкагироведы, «уклоняющиеся» от обсуждения эвенкийского влияния на верхнеколымских и нижнеколымских юкагиров. Взгляды В.Г. Богораза на юкагиров и чуванцев в целом соответствуют мнениям современных археологов. А.И. Лебединцев считает автохтонным населением Северо-Востока Азии чукчей, коряков и эскимосов (Лебединцев 2008: 77), а юкагиров и чуванцев причисляет к более поздним пришельцам; О.А. Мудрак отмечает, что юкагирский язык, вопреки мнению его коллег (Николаева 1988), относится не к уральской ветви, а входит в одну «палеоазиатскую» группу с нивхским (Мудрак 2000). В этом случае лексические связи юкагирского и чукотского языков, проявляющиеся в географических апеллятивах (Бурыкин 2013), следует рассматривать как ареальные. Что касается «древне-азиатского» субстрата на Амуре, то он реально прослеживается у южнотунгусских народов. Гидронимы Анюй - так называются приток Амура и две реки, впадающие в Колыму - происходят от чукотского йынройын - «стрелка, место слияния притока с рекой», а название реки Амур (ульч. Мангбу, нан. [Даи] Мангбо - «большая река, сильная вода») - от чукотского Мэйнгывээм - «Большая 
река» (Бурыкин 2013: 362); можно провести аналогии между чукотской соматической лексикой и удэгейской лексикой медвежьего ритуала (Бурыкин 2000).

Наблюдения В.Г. Богораза за традиционными занятиями жителей бассейнов Колымы и Анадыря привели его к следующему обобщению:

На Колыме и на Анадыре все племена, живущие в соседстве с оленными чукчами, каковы юкагиры, тунгусы и даже та пестрая «смешица», которая составилась из обруселых отрывков погибших народностей, усвоивших русский язык, в общем существуют рыболовством (ездовое животное - собака) или сухопутной охотой (ездовое животное - верховой олень при скудном и ограниченном оленеводстве) (Богораз 1934: XXVII).

Интересны суждения В.Г. Богораза относительно разных этнотерриториальных групп в интервале от Чаунской губы до бассейна Анадыря. Он пишет:

Обрусевшие туземцы ${ }^{1}$ по Колыме рассказывают еще о другом вымершем племени, которое они называют Шелаги и от имени которого производится название Шелагского мыса (мыс Эрри) на Ледовитом океане. «Шелаги» были приморским народом и жили где-то на берегу Ледовитого океана. Предполагают, что им принадлежали остатки жилищ на Медвежьих островах, вблизи устья Колымы. Их часто смешивали с Caacet, хотя нет никаких сведений о взаимном отношении двух указанных племен. Туземцы предполагают, что оба племени эмигрировали на восток. Об этом упоминает также Врангель².

Майдель, без видимых оснований, отрицает существование того и другого племени. Он упоминает, однако, почти на той же самой странице, что Петр Мангол, один из его чукотских проводников, утверждал, что в прежние времена на мысе Эрри жили приморские чукчи, которые говорили на языке, отличном от языка современных обитателей ${ }^{3}$.

Затем он упоминает об охотнике Иване Вилигине, который жил в последней четверти XVIII столетия. Этот охотник утверждал, что он знал одного старого человека по имени Корай (опечатка, д.б. Копай. - А.Б.), который считал себя принадлежащим к племени шелагов. Он жил на морском берегу, в 200 километрах от устья Колымы. Майдель считал весь этот рассказ недоразумением.

Туземцы, однако, рассказывают, что на морском берегу к западу от острова Ајо (Айон. - А.Б.) еще существуют развалины, подобные тем, которые находятся на Медвежьих островах ${ }^{4}$, э это подтверждает слова Вилигина.

1 Обрусевшими туземцами Колымы являются преимущественно юкагиры, имеющие большую примесь русской крови, а также часть якутов и чуванцев. Обрусевшие туземцы Анадыря состоят из юкагирских и чуванских элементов с некоторой примесью коряков и русских (прим. 2) (примечание В.Г. Богораза).

2 Wrangell стр. 338 (примечание В.Г. Богораза). Имеется в виду: Wrangell F. Narrative of an Expedition to the Polar Sea... London, 1840.

${ }^{3}$ Г.Л. Майдель, Путешествие по северо-восточной части Якутской области. Приложение к LXXIV тому «Записок Академии Наук», т. I, стр. 331 (ссылка В.Г. Богораза).

${ }^{4}$ Древние жилища на Медвежьих островах по материалам XVIII-XIX вв. описаны в одной из моих (совместно с В.Н. Соловар) работ (Бурыкин, Соловар 2017: 65-68), но, насколько мне известно, еще не обследованы археологами. 
Название Caаcet в его руссифицированном виде будет «чаванцы» или «чаунцы», так что оно почти тождественно со словом «чуванцы». Это племя, в настоящее время почти исчезнувшее, в прежние времена жило где-то между юкагирами и чукчами. Оно занималось оленеводством и, вероятно, было посредствующим звеном между двумя указанными племенами. Остатки оленных чуванцев в настоящее время ассимилировались с коряками и говорят по-коряцки, а чуванцы-рыболовы совершенно обрусели. Несколько слов чуванского языка, приведенных в интересной книге Дьячкова ${ }^{1}$, являются юкагирскими словами. Дьячков был школьным учителем селения Маркова, на среднем течении Анадыря, и сам себя считал чуванцем. На тундре, к западу от Колымы, еще существуют два или три рода юкагиров, которые смешались с тунгусами и в ограниченных размерах занимаются оленеводством. Старые архивные документы Нижне-Колымска, датированные 1770 годом, упоминают «юкагир Ходинского чуванского рода»². В настоящее время единственный существующий чуванский род называется Ходынским ${ }^{3}$ (Богораз 1934: 7).

Здесь признание шелагов и народа Саaсеt самостоятельными этносами является лишь данью времени. Первые - одна из территориальных групп чукчей - чульыльылm, a Caacet, похоже, является самоназванием чаунских чукчей. Насколько мы знаем, юкагиры в районе Чаунской губы не жили и могли появляться там только как проводники русских экспедиций конца XVIII - первой четверти XIX в. Г. Майдель не нашел никаких следов шелагов как отдельного народа - и был в этом прав (см.: Бурыкин 2013: 299-305, 315, 468). Что касается остатков жилищ на Медвежьих островах, то они принадлежали, очевидно, приморским чукчам-ангкальыm, которые в XVIII в. посещали эти острова, занимаясь здесь промыслом (Бурыкин, Соловар 2017: 65-68). Им же принадлежит и странное сооружение, которое геодезисты XVIII в. назвали «крепостцой» (Ф.П. Врангель искал его, но уже не нашел); можно предположить, что это был жертвенный помост, сооруженный приморскими чукчами (Бурыкин 2011).

Характеризуя названия и самоназвания народов Чукотки, В.Г. Богораз отмечает: «Юкагиры сами себя называют odul - “человек”. В чукотско-коряцкой огласовке получится: atal» (Богораз 1934: 8, прим. 1). А чуть ниже пишет:

Ламуты и тунгусы называются qaa-ramkьt, что значит «оленное племя». Более точно ламуты называются qor-emte-qaa-ramkbt - «оленное племя, ездящед верхом на оленях», а тунгусы тундры к западу от Колымы вместе с оленными юкагирами называются orwu-qaa-ramkst - «санно-оленное племя», так как они ездят на санях. Юкагиры не имеют специального названия. Их называют veemьlьt - «речной народ», также как называют северных русских, потому что те и другие являются рыболовами и живут по рекам или вблизи от них (Богораз 1934: 8).

Здесь весьма существенны как использование названия вээмыльыл («речные, приречные»), так и вытекающее из него указание на юкагирское происхождение

${ }^{1}$ Дьячков, стр. 101 (примечание В.Г. Богораза). Имеется в виду «Повесть об Афанасии Дьячкове, жителе села Марково, учителе, историке-краеведе, этнографе (1840-1907 гг.)» (Жихарев 1992: 101).

2 Доктор Кибер, один из спутников Врангеля, говорит, что «чуванцы - юкагирского племени. Языки их весьма схожи. Я знал одного чуванца, который без предварительного знакомства с юкагирами мог легко сообщаться с ними. Одежда чуванцев внутри страны подобна чукотской» (примечание В.Г. Богораза).

${ }^{3}$ В отписке Семена Дежнева якутскому воеводе от половины XVII века упоминается еще одно чуванское племя или род: Анаулы (примечание В.Г. Богораза). 
анаулов, живших по берегам р. Белой. Сведения об анаулах крайне скудны, однако известно, что их военное дело и военный опыт намного превосходили уровень, достигнутый другими группами юкагиров (Там же: 41-42).

Очень важные сведения приводит В.Г. Богораз относительно демографии юкагиров, а также их связей с соседними народами и изменений в традиционном хозяйстве. Ученый пишет о низкой рождаемости и постепенном вымирании юкагирских племен, с приходом русских положение которых усугубилось. Появление смешанных браков, отмечает Владимир Германович, -

...недавнее и не весьма частое. Рождаемость при браках с русскими женщинами (вернее, с обрусевшими юкагирами) - незначительна. Причиной этого, вероятно, служит то обстоятельство, что юкагирские женщины, мало плодовитые и в привычных для них условиях жизни, становятся еще менее способными к деторождению в условиях чукотской кочевой жизни <..>

Туземцы сокращали промысла и терпеливо подчинялись регулярным голодовкам, считая свое племя обреченным к вымиранию. Среди вымирающих юкагирских родов на нижней Колыме количество безбрачных непропорционально велико. Охота на диких оленей и линялую птицу у юкагиров в значительной степени выходит из практики, потому что требует слишком большого напряжения сил. Колымские юкагиры живут почти исключительно рыболовством и каждую весну голодают. Не следует, однако, забывать того, что и до прихода русских прирост населения даже у наиболее сильных племен был весьма сомнительным и многие племена вымирали, от постоянных междуплеменных войн и голодовок (Богораз 1934: 19-20).

Анализируя причины появления смешанных браков, ниже ученый пишет:

Юкагиры еще беднее, чем тунгусы. Для юкагирского юноши является несомненным счастьем, если его примет в зятья какая-нибудь оленеводческая чукотская семья. Мне известно около двадцати случаев брака между чукчами и русскими мещанами или обрусевшими туземцами. Половина этих случаев относится к настоящему времени, половина к недавнему прошлому. Я посетил одну за другой все смешанные чукотско-русские семьи в разных частях чукотской территории. В подавляющем большинстве случаев русская или обрусевшая женщина вышла замуж за чукчу. Все эти женщины вышли из очень бедных семей. Брак с оленеводами служил им средством хотя бы на время избавить семью от постоянной голодовки. За некоторых из этих женщин уплатили по двадцати и тридцати убитых оленей, за других же - только по два или по три (Там же: 129).

О крайне бедственном положении юкагиров Владимир Германович пишет и в своем романе «Воскресшее племя» (Богораз 1935). Переиздаваемый лишь изредка, этот роман остается крайне актуальным и сегодня, это ценнейший памятник истории науки и просвещения Российского Севера (Бурыкин 2012). Дополнением к характеристике экономического положения юкагиров, данной в первой части монографии «Чукчи», служит следующий пассаж:

О случаях каннибализма среди чукоч мне не пришлось слышать, хотя, голодовки, уничтожившие целые селения, были еще свежи в их памяти, отно- 
сительно юкагирских семей, голодавших в 1895 году на Среднем Омолоне, известны случаи самого зверского каннибализма. Не было у чукоч также ни одного случая подкидывания новорожденных девочек (Богораз 1934: 27-28).

Описанная В.Г. Богоразом практика «подкидывания» новорожденных девочек соотносится с наблюдениями Ф.П. Врангеля и Ф.Ф. Матюшкина. Так, Ф.П. Врангель в «Путешествии по северным берегам Сибири и по Ледовитому морю...» писал: «Между прочим было здесь обыкновение привешивать новорожденных детей женского пола в корзинах к деревьям, где они и погибали, если только не бывали замечены посторонними. И теперь еще во многих семействах есть несколько женщин, спасенных проходящими» (Врангель 1948: 212, прим.).

Не обошел вниманием В.Г. Богораз и медицинские практики юкагиров и чукчей. О характерном заболевании женщин «менерике» или «эмирячении» он заметил:

Хорошо известная форма северной истерии, которая так распространена среди юкагирских и ламутских женщин, редко встречается среди чукоч, среди оленных чукоч почти совсем не встречается. Эта болезнь выражается в безудержном желании повторять громким голосом каждое слово, слышимое от кого-нибудь, и подражать всякому неожиданному жесту или действию. Женщины из обруселых туземцев и женщины русские часто страдают этой болезнью, но чукотские женщины счастливо избежали ее $<\ldots .>$ Чукчи не знают никаких медицинских средств, исключая средств магических, чем отличаются от камчадалов и обрусевших юкагиров, которые употребляют в качестве медикаментов многие растения и минералы (Богораз 1934: 24-25).

В своих работах В.Г. Богораз уделяет внимание элементам материальной культуры юкагиров. Так, в первом томе монографии «Чукчи», описывая изготовление лодок колымскими юкагирами, он замечает:

В общем это было кораблестроение эпохи неолита. Кстати сказать, до самого последнего времени речные карбасья (лодки) колымских и анадырских поречан русско-юкагирского происхождения строятся по точно такому же методу. Мало того, верхне-колымские юкагиры, племя совсем умирающее, находящееся почти при последнем издыхании, заимствовали это унылое строительство у нижне-колымских русских и сделали его своей собственной специальностью. Верхне-колымские лодки юкагирского дела сплавляются вниз по Колыме за тысячу верст и охотно раскупаются по средним и нижним поселкам. Строительство крупных судов потерялось уже в самом начале XVIII века (Богораз 1934: 37).

Без сомнения, прекращение строительства кочей было связано с фактическим прекращением арктического мореплавания после гибели Н.П. Шалаурова вблизи устья Колымы (1764 г.).

В.Г. Богораз внимательно изучал материалы, связанные с военными столкновениями русских и выступающих на их стороне юкагиров с чукчами и коряками (Богораз 1934: 41-42, 44). Рассматривая документы, относящиеся к деятельности Д.И Павлуцкого (руководителя русской экспедиции на Чукотку), Владимир Германович находит свидетельства возврата юкагирами своих людей, попавших к чукчам:

...он [Д.И Павлуцкий] описывает, как анадырские юкагиры приходили к чукчам выкупать своих пленных. Юкагиры приносили табак, котлы, ножи, топо- 
ры, луки, стрелы и бусы. Они выкупили девять человек. Чукчи были очень довольны и дали юкагирам одежды из пыжиков, белые пыжиковые шкуры, белые камусы, кухлянки из куньего меха, красных лисиц (Богораз 1934: 50).

Ценны свидетельства В.Г. Богораза относительно причин и условий продвижения чукчей на запад к устью Колымы. Он пишет:

В 30-х годах XIX века их стойбища простирались уже до реки Большой Баранихи, хотя вся эта область с древних времен считалась принадлежащей анюйским юкагирам. В 50-х годах XIX века чукчи продвинулись сперва на Лабуген, а потом на Погинден [Погынден]. Обе эти реки являются притоками Сухого Анюя. Продвижение чукоч связано с исчезновением юкагиров. Последние или вымерли или отступили к Колыме, так как стада диких оленей прекратили свой ежегодный путь через реки Анюй и Колыму. Это, вероятно, зависело от возрастания чукотских стад. Таким образом умиротворение страны оказалось неблагоприятным для более первобытного хозяйства юкагирских охотников и было весьма благоприятно для кочевого хозяйства чукоч, которое было, конечно, выше, чем хозяйство юкагиров, хотя в других отношениях чукчи являлись более примитивным народом (Богораз 1934: 59).

В первой части своей монографии «Чукчи», изданной на русском языке в 1934 г., ученый весьма выразительно освещает и языковую ситуацию на Нижней Колыме, с которой столкнулись первые русские проповедники:

Отец Виктор совершенно не знал ни чукотского языка, ни даже торгового русско-чукотского жаргона. Другой миссионер, отец Венедикт, должен был заниматься западными, оленными чукчами. Он жил, как упомянуто выше, на окраине западной тундры, в якутском селении Сен-Кюэль. Часть оленных чукоч время от времени подкочевывала к его месту жительства, и тогда он пытался войти с ними в общение. Для этой цели ему были нужны два переводчика: один переводил с русского на якутский. Любой мещанин или казак из Средне-Колымска был совершенно пригоден для этой цели, так как средне-колымчане вполне двуязычны. Другой переводчик, обыкновенно из тундренных юкагиров, живущих в постоянном соседстве с чукчами, переводил с якутского на чукотский. Сквозь это двойное посредство отец Венедикт пытался проповедывать слово божие своей чукотской пастве. Выходило, должно быть, не весьма вразумительно (Богораз 1934: 74).

Весьма интересны и оригинальны описания религиозных представлений юкагиров, содержащиеся в материалах по шаманству, собранных В.Г. Богоразом в 19341936 гг. и опубликованных в 2018 г. Ученый отмечает: «Душа у юкагиров имеет тройной состав. Старик Таулях с реки Ясачной говорил Иохельсону следующее: “Есть три души «аиби»: одна душа живет в голове, другая в сердце, третья пропитывает все тело”» (Богораз 2018: 256). И далее: «Например, мне говорил один тунгусо-юкагирский шаман: “Моя душа как бы имеет тысячу рук, они простерты во все концы вселенной и охватывают все мироздание”» (Там же: 393). У эвенов аналогичных представлений не отмечено.

Говоря о духах-хозяевах - характерном компоненте анимизма, В.Г. Богораз пишет: 
Представления о «хозяевах» мест развиты также среди обруселых юкагиров Колымы и Анадыря. По всей вероятности, первоначальная туземная основа переплелась с русскими мифологическими представлениями. Здесь мы видим «хозяев» вполне человекоподобных, но гораздо сильнее человека < .. $>$ «Хозяин» леса, по русско-юкагирским представлениям, имеет большую склонность к водке и карточной игре. Обруселые туземцы утверждают, что охотники, которым исключительно везет на промысле, очевидно, купили свою удачу у лесного хозяина за водку или за колоду карт. «Хозяева» лесов играют в карты друг с другом. Ставки их - различные породы зверей. Они переходят от одного к другому в процессе игры. Этим объясняются частые перекочевки зверя (Богораз 1939: 9).

С другой стороны, в юкагирском фольклоре встречаются эпизоды, в которых горы не подчинены «хозяину», а выступают как самостоятельные человекоподобные существа, окаменевающие в конце рассказа (Богораз 1939: 10). Здесь автор напоминает о традиционных антропоморфных (или рассматриваемых в таком качестве) камнях или скалах, составляющих универсальную для народов Сибири иерофанию (почитаемое место) (см.: Островский 1997: 19, 29, 242).

В.Г. Богораз сопоставляет чукотских духов-кэлет с юкагирскими «сказочными стариками» - практически единственными сверхъестественными персонажами юкагирского фольклора (Богораз 1939: 17-18). В избранных трудах по шаманству (опубликованы на основании архивных материалов ученого за 1934-1936 гг.) он пишет:

Юкагирские злые духи тоже, по указанию Иохельсона, соответствуют чукотским Kelet и коряцким Kalan. Они называются «Kukul» (на тундренном наречии «Korel»). Некоторые из этих духов имеют обособленный образ. Таков, например, «ninjuoje» - это злой дух, обитающий в человеческой одежде, спрятавшись в ее складках. Он причиняет суставный ревматизм. Особый класс злых духов «јоibe». Этим словом обозначаются злые духи других народов, в особенности русские заразные болезни: оспа, корь, грипп. Эти чужие духи гораздо страшнее местных юкагирских духов, так как против них юкагирские шаманы бессильны (Богораз 2018: 302, 303).

У юкагиров, по указаниям Иохельсона, духи-помощники по большей части духи животных и птиц. Они называются так же. Среди этих духов есть и душа мамонта, «хольчут-акбы». С другой стороны, шаману помогают также духи умерших, в особенности духи умерших родственников, бывших шаманами, - «Алман-аиби». Последние - самые могучие покровители шамана (Там же: 312 ).

В.Г. Богораз также отмечает, что культ бурого (по его словам, «черного») медведя пришел к чукчам от юкагиров, у которых этот медведь составляет «предмет глубочайшего почитания» (Богораз 1939: 36-37). К злым духам, как и у коряков, у юкагиров относится мамонт (Там же: 38 ).

О шаманстве у юкагиров находим сведения в архивных материалах ученого, изданных в 2018 г. А во второй части монографии «Чукчи», вышедшей на русском языке в 1939 г. читаем:

В каждой юкагирской семье также имелся бубен. Во время путешествий в районе Омолона и обоих Анюев я находил бубны в старых, полуразрушенных поселках, население которых вымерло от голода в десятых годах девятнадцатого столетия, после того, как дикие олени почти совершенно исчезли в этом районе. 
Мой товарищ по путешествию, обрусевший туземец с Колымы, затруднялся дать объяснение такому большому количеству найденных нами бубнов и настойчиво повторял, что эти люди, должно быть, все были шаманами и не удивительно, что бог убрал их со света. Однако это несомненно были семейные бубны, которые употреблялись так же, как и у современных чукоч (Богораз 1939: 105-106).

Следует иметь в виду, что сообщение Я.И. Линденау о том, что юкагиры будто бы изготавливали бубны из кожи умерших шаманов (Линденау 1983: 155), не соответствует действительности, хотя бы из-за размеров юкагирского бубна, сходного с эвенским. Тем не менее В.Г. Богораз подтверждает обычай юкагиров хранить останки умерших в мешках в качестве амулетов (Богораз 1939: 180-181, 2018: 258-260).

Ученый приводит описание уникальной дощечки с зооморфными изображениями, использовавшейся в шаманской практике (была передана в МАЭ; утрачена): «...красная сторона дощечки представляла собою белое шаманство и употреблялась при врачевании, черная сторона обозначала черное шаманство и применялась для наведения злых чар» (Богораз 1939: 39); «[н]апомню также магическую доску, употребляемую юкагирскими шаманами: одна половина ее окрашена красной краской, а другая - черной, что символизирует доброе и злое шаманство» (Там же: 118); «[д] ве выемки на грани между половинами дощечки были следами некогда вставленных в нее кусков серебра, как объяснили мне старики из деревни» (Там же: 38). Последнее описание вызывает вопросы и требует пояснения, поскольку не ясно, как серебро попало к юкагирам, если в окрестностях, несмотря на проведенные изыскания, геологами серебро обнаружено не было (Бурыкин 2013: 227-234).

Объяснение функций этой явно юкагирской дощечки В.Г. Богораз дает исходя из противопоставления белого и черного шаманства. Но, насколько мы знаем, у юкагиров такого противопоставления не было (Бурыкин, Жукова 2000), как не было его и у эвенов. У чукчей, как отмечал сам В.Г. Богораз, одни и те же шаманы совмещали принесение пользы и причинение зла (Богораз 1939: 118), позже об этом писал и ученик Владимира Германовича И.С. Вдовин (Вдовин 1981: 186-189). И.С. Вдовин, однако, считал, что практика причинения зла вообще не относится к шаманской.

Анализируя торговые отношения чукчей с соседями, В.Г. Богораз упоминает и юкагиров:

Впрочем, эти многооленные специализированные хозяева собирают в обилии наилучшую пушную валюту, необходимую им для торговли с факторными. В первую очередь они скупают песцов, также красных лисиц, горностаев и белок, собирая ее от беднейших соплеменников, а также от других соседних народностей: ламутов, тунгусов, юкагиров и даже русских (Богораз 1934: XXV), а предлагаемый ими товар характеризуется ученым так: «Чукчи до сих пор не знают кузнечного промысла. Тунгусы и юкагиры, отчасти коряки куют из различных обломков старого железа ножи, тесла и именно во время голодовок выменивают их у богатого оленного соседа на мясо для себя и своих собак» (Там же: XXVII). Однако подобная деятельность юкагиров не только не поощрялась, но и пресекалась: «...в 1834 году, нижнеколымские казаки подали жалобу даже на юкагиров с поселка Еломбал на Большом Анюе оттого, что юкагиры, чтобы добыть себе пищу, ковали железо и готовый продукт продавали чукчам. И это было немедленно запрещено» (Там же: 57). Эта информация, по всей вероятности, была почерпнута автором из какого-то архивного источника. 
Сведения о культуре юкагиров, представленные в трудах В.Г. Богораза, основываются на его собственных полевых наблюдениях, а поэтому обладают большой ценностью. Поскольку основной целью ученого было изучение и описание этнографии чукчей, заметки о юкагирах оказались «рассыпанными» по страницам его главного труда - монографического исследования «Чукчи». Тем не менее многие наблюдения и рассуждения В.Г. Богораза уникальны и весьма полезны для изучения духовной и материальной культуры не только юкагиров, но и других этнических групп, населявших Чукотку во второй половине XIX в.

\section{Источники и материалы}

Богораз 1935 - Богораз В.Г. Воскресшее племя. М.: Художественная литература, 1935.

Врангель 1948 [1841] - Врангель Ф.П. Путешествие по северным берегам Сибири и по Ледовитому морю, совершенное в 1820, 1821, 1822, 1823 и 1824 г.г. экспедицией под начальством флота лейтенанта Ф.П. Врангеля / Под общ. ред. контр-адмирала Е. Шведе. Л.: Изд-во Главсевморпути, 1948 [1841].

Жихарев 1992 - Жихарев Н.А. Повесть об Афанасии Дьячкове, жителе села Марково, учителе, историке-краеведе, этнографе (1840-1907 гг.). Магадан. Магаданское книжное издательство. 1992.

Уваровская 1992 - Уваровская Л.П. Сказания села Снежное (сказки и легенды) / Сост. Н. Воронцова. Анадырь: Чукотский окружной центр народного творчества, 1992.

\section{Научная литература}

Беликов Л.В. В.Г. Богораз как собиратель и исследователь чукотского фольклора // Ученые записки ЛГПИ им. А.И. Герцена. Т. 353. Л.: ЛГПИ, 1967. С. 80-89.

Богораз В.Г. Древние переселения народов в северной Евразии и в Америке // Сборник Музея антропологии и этнографии АН СССР. Т. VI: 1927 г. / Отв. ред. Е.Ф. Карский. Л.: Музей антропологии и этнографии, 1927. С. 37-62.

Богораз В.Г. Чукчи. Ч. 1. Л.: Изд-во ИНСа, 1934.

Богораз В.Г. Чукчи. Ч. 2. Л.: Изд-во ИНСа, 1939.

Богораз В.Г. Избранные труды В.Г. Богораза по шаманству (1934-1936 гг.) (из архива) / Подг. М.М. Шахнович, Е.А. Терюковой. СПб.: Изд-во С.-Петербургского ун-та, 2018.

Бурыкин А.А. Рец. на: Кормушин И.В. Удыхейский (удэгейский) язык. М., 1998 // Известия РАН, Серия: Литература и языки. 2000. № 2. С. 69-73.

Бурыкин A.A. Ритуал поклонения головам добытых животных и «праздник голов» у чукчей (опыт анализа разнохарактерных источников) // Праздники и обряды как феномен этнической культуры: материалы Десятых Санкт-Петербургских этнографических чтений / Отв. ред. В.М. Грусман, Е.Е. Герасименко. СПб.: РЭМ, 2011. С. 78-81.

Бурыкин А.А. Север и коренные северяне первой трети XX века в романе В.Г. Богораза «Воскресшее племя» // Проблемы межлитературного взаимодействия (памяти профессора М.Г. Михайловой): сборник материалов I Всероссийской научно-практической интернет-конференции (г. Якутск, 19-24 марта 2012 г.) / Отв. ред. О.В. Дедюхина, О.И. Иванова. Якутск: СВФУ, 2012. С. 15-19.

Бурыкин А.А. Имена собственные как исторический источник. По материалам русских документов об открытии Сибири и Дальнего Востока XVII-XIX вв. СПб.: Петербургское востоковедение, 2013.

Бурыкин А.А., Жукова Л.Н. К изучению шаманства юкагиров // Актуальные проблемы филологии. Якутск: Изд-во Якутского ун-та, 2000. Вып. 3. С. 127-132.

Бурыкин А.А., Соловар В.Н. Исследования по этнографии и фольклору народов Северо-Западной Сибири / Отв. ред. Д.А. Функ. Тюмень: ФОРМАТ, 2017. 
Вдовин И.С. Чукотские шаманы и их социальные функции // Проблемы истории общественного сознания аборигенов Сибири / Отв. ред. И.С. Вдовин. Л.: Наука, 1981. С. 178-217.

Жукова Л.Н. Юкагиры - наследники циркумполярной культуры Северной Евразии // Илин. 2003. № 1 (32). С. 80-82.

Жукова Л.Н. Очерки по юкагирской культуре. Ч. 1: Одежда юкагиров: генезис и семантика / Отв. ред. М.А. Кирьяк. Новосибирск: Наука, 2009.

Жукова Л.Н. Очерки по юкагирской культуре. Ч. 2: Мифологическая модель мира / Отв. ред. А.Н. Алексеев. Новосибирск: Наука, 2012.

Жукова Л.Н. Очерки по юкагирской культуре. Ч. 3 / Отв. ред. М.А. Кирьяк. Якутск: Бичик, 2013.

Зеленин Д.К. В.Г. Богораз - этнограф и фольклорист // Памяти В.Г. Богораза. 1865-1936 / Отв. ред. И.И. Мещанинов. М.; Л.: Изд-во АН СССР, 1937. С. V-XVI.

Иохельсон В.И. Юкагиры и юкагиризированные тунгусы / Пер. с англ., отв. ред. Н.А. Алексеевю Новосибирск: Наука, 2005.

Кирьяк М.А. Археология Западной Чукотки в связи с юкагирской проблемой. М.: Наука, 1993.

Колесницкая И.М. В.Г. Богораз-Тан - фольклорист // Очерки по истории русской этнографии, фольклористики и антропологии. Вып. 5 / Отв. ред. В.К. Соколова. М.: Изд-во АН СССР, 1971. С. 139-159.

Крупник И.И. В.Г. Богораз, его наследие и ученики // Тропою Богораза: научные и литературные материалы / Ред. Л.С. Богословская, В.С. Кривощеков, И.И. Крупник. М.: Институт наследия - ГЕОС, 2008. С. 17-22.

Лебединцев А.И. Проблема происхождения северо-восточных палеоазиатов // Вестник СВНЦ ДВО РАН. 2008. № 3. С. 67-80.

Линденау Я.И. Описание народов Сибири (первая половина XVIII века): историко-этнографические материалы о народах Сибири и Северо-Востока (1740-е гг.). Магадан: Магаданское книжное изд-во, 1983.

Михайлова Е.А. В.Г. Богораз: ученый, писатель, общественный деятель // Выдающиеся отечественные этнологи и антропологи XX в // Отв. ред. В.А. Тишков, Д.Д. Тумаркин. М.: Наука, 2004. С. 95-136.

Михайлова Е.А. Софья Константиновна Богораз (1870-1921): штрихи к портрету Владимира Германовича Богораза // Антропологический форум. 2016. № 29. С. 109-124.

Мудрак O.A. Юкагиры и нивхи (проблема палеоазиатов) // Проблемы изучения дальнего родства языков на рубеже третьего тысячелетия: доклады и тезисы научной конференции 29 мая -2 июня 2000 г. // Сост. Г.А. Старостин, С.А. Старостин. М.: РГГУ, 2000. С. 133-148.

Николаева И.А. Проблема урало-юкагирских генетических связей. Автореф. дис. ... канд. филол. наук. Институт языкознания Ан СССР, Москва, 1988.

Окладников А.П. (ред.) Юкагиры. Историко-этнографический очерк. Новосибирск: Наука, 1975.

Островский А.Б. Мифология и верования нивхов. СПб.: Центр «Петербургское Востоковедение», 1997.

Плужников Н.В., Шадрин В.И. Юкагиры // Народы Северо-Востока Сибири / Отв. ред. Е.П. Батьянова, В.А. Тураев. М.: Наука, 2010. С. 677-685.

Туголуков В.A. Кто вы, юкагиры? М.: Наука, 1979.

Цинциус В.И. В.Г. Богораз как исследователь эвенского языка // Ученые записки ЛГПИ им. А.И. Герцена. Т. 353. Л.: ЛГПИ, 1967. С. 90-95.

Bogoras V.G. Tales of Jukagir, Lamut, and Russianized Natives of Eastern Siberia // Anthropological Papers of the American Museum of Natural History. Vol. XX (I). N.Y.: The Trustees, 1918. P. 136-148.

Kan S. "My Old Friend in a Dead-end of Empiricism and Skepticism": Bogoras, Boas, and the Politics of Soviet Anthropology of the Late 1920s - Early 1930s// Histories of Anthropology Annual. 2006. Vol. 2. P. 33-68. 


\section{References}

Belikov, L.V. 1967. V.G. Bogoraz kak sobiratel' i issledovatel' chukotskogo fol'klora [V.G. Bogoraz as a Collector and Researcher of Chukchi Folklore]. Uchenye zapiski LGPI im. A.I. Gertsena 353: 80-89.

Bogoras, V.G. 1918. Tales of Jukagir, Lamut, and Russianized Natives of Eastern Siberia. In Anthropological Papers of the American Museum of Natural History XX (I): 136-148. New York: The Trustees.

Bogoraz, V.G. 1927. Drevnie pereseleniia narodov v severnoi Evrazii i v Amerike [Ancient Migrations of Peoples in Northern Eurasia and America]. In Sbornik Muzeia antropologii $i$ etnografii AN SSSR [Collection of the Museum of Anthropology and Ethnography]. Vol. VI, 1927 g. [1927], edited by E.F. Karskii, 37-62. Leningrad: Muzei antropologii i etnografii.

Bogoraz, V.G. 1934. Chukchi [Chukchi]. Pt. 1. Leningrad: Izdatelstvo Instituta Narodov Severa.

Bogoraz, V.G. 1939. Chukchi [Chukchi]. Pt. 2. Leningrad: Izdatelstvo Instituta Narodov Severa.

Bogoraz, V.G. 2018. Izbrannye trudy V.G. Bogoraza po shamanstvu (1934-1936 gg.) (iz arkhiva) [From the Archive: Selected Works of V.G. Bogoraz on Shamanism (1934-1936)], edited by M.M. Shakhnovich and E.A. Teriukova. St. Petersburg: Izdatel'stvo Sanrt-Peterburgskogo universiteta.

Burykin, A.A. 2000. Review of Udykheiskii (udegeiskii) yazyk [Udyxeysky (Udege) Language)], by I.V. Kormushin. M., 1998 // Izvestiia RAN, Seriia: Literatura i yazyki 2: 69-73.

Burykin, A.A. 2011. Ritual pokloneniia golovam dobytykh zhivotnykh i "prazdnik golov" u chukchei (opyt analiza raznokharakternykh istochnikov) [Ritual of Worshipping the Heads of Extracted Animals and the "Feast of Heads" in the Chukchi (Experience of Analyzing Different Sources)]. In Prazdniki i obriady kak fenomen etnicheskoi kul 'tury: materialy Desiatykh SanktPeterburgskikh etnograficheskikh chtenii [Holidays and Rituals as a Phenomenon of Ethnic Culture: Materials of the $10^{\text {th }}$ St. Petersburg Ethnographic Readings], edited by V.M. Grusman and E.E. Gerasimenko, 78-81. St. Petersburg: REM.

Burykin, A.A. 2012. Sever i korennye severiane pervoi treti XX veka v romane V.G. Bogoraza "Voskresshee plemia" [The North and Native Northerners Early $20^{\text {th }}$ Century in the Novel of V.G. Bogoras "The Resurrected Tribe"]. In Problemy mezhliteraturnogo vzaimodeistviia (pamiati professora M.G. Mikhailovoi): sbornik materialov I Vserossiiskoi nauchno-prakticheskoi internet-konferentsii (g. Yakutsk, 19-24 marta 2012 g.) [Problems of Interliterary Interaction (In Memory of Professor M.G. Mikhailova): Collection of Materials of the I All-Russian Scientific and Practical Internet Conference (Yakutsk, March 19-24, 2012)], edited by O.V. Dediukhina and O.I. Ivanova, 15-19. Yakutsk: SVFU.

Burykin, A.A. 2013. Imena sobstvennye kak istoricheskii istochnik. Po materialam russkikh dokumentov ob otkrytii Sibiri i Dal'nego Vostoka XVII-XIX vv. [Proper Names as a Historical Source: Based on the Materials of Russian Documents on the Discovery of Siberia and the Far East of the $17-19^{\text {th }}$ Centuries]. St. Petersburg: Peterburgskoe vostokovedenie.

Burykin, A.A., and L.N. Zhukova. 2000. K izucheniiu shamanstva yukagirov [To the Study of Shamanism of the Yukagirs]. Aktual'nye problemy filologii [Actual Problems of Philology] 3: 127-132. Yakutsk: Izdatel'stvo Yakutskogo universiteta.

Burykin, A.A., and V.N. Solovar. 2017. Issledovaniia po etnografii i fol'kloru narodov SeveroZapadnoi Sibiri [Researches on Ethnography and Folklore of the Peoples of North-Western Siberia], edited by D.A. Funk. Tiumen': FORMAT.

Iokhelson, V.I. 2005. Yukagiry i yukagirizirovannye tungusy [Yukagirs and Yukagirized Tungus], edited by N.A. Alekseev. Novosibirsk: Nauka.

Kan, S. 2006. "My Old Friend in a Dead-end of Empiricism and Skepticism": Bogoras, Boas, and the Politics of Soviet Anthropology of the Late $1920^{s}$ - Early 1930s. Histories of Anthropology Annual 2: 33-68.

Kiriiak, M.A. 1993. Arkheologiia Zapadnoi Chukotki v sviazi s yukagirskoi problemoi [Archeology of Western Chukotka in Connection with the Yukagir Problem]. Moscow: Nauka.

Kolesnitskaia, I.M. 1971. V.G. Bogoraz-Tan - fol'klorist [V.G. Bogoraz-Tan - folklorist]. In Ocherki po istorii russkoi etnografi, fol'kloristiki $i$ antropologii [Essays on the History of Russian Ethnography, Folklore and Anthropology], edited by V.K. Sokolova, 5: 139-159. Moscow: Izdatel'stvo AN SSSR. 
Krupnik, I.I. 2008. V.G. Bogoraz, ego nasledie i ucheniki [V.G. Bogoraz, His Legacy and Disciples]. In Tropoiu Bogoraza: nauchnye i literaturnye materialy [On the Path of Bogoraz: Scientific and Literary Materials], edited by L.S. Bogoslovskaia, V.S. Krivoshchekov, and I.I. Krupnik, 17-22. Moscow: Institut naslediia - GEOS.

Lebedintsev, A.I. 2008. Problema proiskhozhdeniia severo-vostochnykh paleoaziatov [The Problem of the Origin of North-Eastern Paleoasiates]. Vestnik SVNTS DVO RAN 3: 67-80.

Lindenau, Y.I. 1983. Opisanie narodov Sibiri (pervaia polovina XVIII veka): istoriko-ehtnograficheskie materialy o narodakh Sibiri i Severo-Vostoka (1740-e gg.) [Description of the Peoples of Siberia (The First Half of the $18^{\text {th }}$ Century): Historical and Ethnographic Materials About the Peoples of Siberia and the North-East $\left(1740^{\mathrm{s}}\right)$ ]. Magadan: Magadanskoe knizhnoe izdatel'stvo.

Mikhailova, E.A. 2004. V.G. Bogoraz: uchenyi, pisatel', obshchestvennyi deiatel' [V.G. Bogoraz: Scientist, Writer, Public Figure]. In Vydaiushchiesia otechestvennye etnologi $i$ antropologi XX v. [Outstanding Russian Ethnologists and Anthropologists of the $20^{\text {th }}$ Century], edited by V.A. Tishkov and D.D. Tumarkin, 95-136. Moscow: Nauka.

Mikhailova, E.A. 2016. Sofia Konstantinovna Bogoraz (1870-1921): shtrikhi k portretu Vladimira Germanovicha Bogoraza [Sofya Konstantinovna Bogoraz (1870-1921): Touches to the Portrait of Vladimir Germanovich Bogoraz]. Antropologicheskii forum 29: 109-124.

Mudrak, O.A. 2000. Yukagiry i nivkhi (problema paleoaziatov) [The Yukaghir and Nivkh (Problem of Paleosiberians)]. In Problemy izucheniia dal'nego rodstva yazykov na rubezhe tret'ego tysiacheletiia: doklady i tezisy nauchnoi konferentsii 29 maia -2 iiunia $2000 \mathrm{~g}$. [Problems of Studying the Distant Relationship of Languages at the Turn of the Third Millennium: Reports and Abstracts of a Scientific Conference May 29 - June 2, 2000], edited by G.A. Starostin and S.A. Starostin, 133-148. Moscow: RGGU.

Nikolaeva, I.A. 1988. Problema uralo-yukagirskikh geneticheskikh sviazei [The Problem of UralYukagir Genetic Relations]. PhD diss. abstract. Institute of Linguistics, Academy of Science SU.

Okladnikov, A.P. 1975. Yukagiry. Istoriko-etnograficheskii ocherk [The Yukaghirs: Historical and Ethnographic Essay]. Novosibirsk: Nauka.

Ostrovskii, A.B. 1997. Mifologiia i verovaniia nivkhov [Mythology and Beliefs of the Nivkhs]. St. Petersburg: Tsentr "Peterburgskoe Vostokovedenie".

Pluzhnikov, N.V., and V.I. Shadrin. 2010. Yukagiry [The Yukagirs]. In Narody Severo-Vostoka Sibiri [Peoples of the North-East of Siberia], edited by E.P. Batianova and V.A. Turaev, 677685. Moscow: Nauka.

Tsintsius, V.I. 1967. V.G. Bogoraz kak issledovatel' evenskogo yazyka [V.G. Bogoraz as a Researcher of the Even Language]. Uchenye zapiski LGPI im. A.I. Gertsena 353: 90-95.

Tugolukov, V.A. 1979. Kto vy, yukagiry? [Who are You, Yukagirs?]. Moscow: Nauka.

Vdovin, I.S. 1981. Chukotskie shamany i ikh sotsial'nye funktsii [Chukchi Shamans and Their Social Functions]. In Problemy istorii obshchestvennogo soznaniia aborigenov Sibiri [Problems of the History of Social Consciousness of the Aborigines of Siberia], edited by I.S. Vdovin, 178-217. Leningrad: Nauka.

Zelenin, D.K. 1937. V.G. Bogoraz - etnograf i fol'klorist [V.G. Bogoraz - Ethnographer and Folklorist]. Pamiati V.G. Bogoraza. 1865-1936 [In Memory of V.G. Bogoraz. 1865-1936], edited by I.I. Meshchaninov, V-XVI. Moscow; Leningrad: Izdatel'stvo AN SSSR.

Zhukova, L.N. 2003. Yukagiry - nasledniki tsirkumpoliarnoi kul'tury Severnoi Evrazii [Yukagirs Heirs of Circumpolar Culture of Northern Eurasia]. Ilin 1 (32): 80-82.

Zhukova, L.N. 2009. Ocherki po yukagirskoi kul'ture [Essays on the Yukagir Culture]. Pt. 1, Odezhda yukagirov: genezis i semantica [Clothing of the Yukagirs], edited by M.A. Kiriiak. Novosibirsk: Nauka.

Zhukova, L.N. 2012. Ocherki po yukagirskoi kul'ture [Essays on the Yukagir Culture]. Pt. 2, Mifologicheskaia model' mira [Mythological Model of the World], edited by A.N. Alekseev. Novosibirsk: Nauka.

Zhukova, L.N. 2013. Ocherki po yukagirskoi kul'ture [Essays on the Yukagir Culture]. Pt. 3, edited by M.A. Kiriiak. Yakutsk: Bichik. 